\title{
ENERGY EVALUATION OF THE MUNICIPAL SOLID WASTE PYROLYSIS
}

This contribution deals with possibilities of using pyrolysis as a method for municipal solid waste (MSW) disposal. Taking into account the possibilities of MSW separation, specific sorts of wastes were selected and subjected to laboratory experiments. The main aim of experimental measurements was to determine the distribution of the caloric value of an original sample in the products of pyrolysis. The aim of this research was to determine the energy content of selected MSW sorts and to recommend the method of their thermal disposal.

Key words: pyrolysis, municipal solid waste, caloric value, human environment

\section{Introduction}

Worsening environmental situation in the whole world is caused mainly by the excessive and continually rising amount of waste. The European Union program of waste management includes also a strategic plan aimed at solving this problem, with possible use of waste for energy production. When there is no possibility to prevent the production of waste or to recycle waste, the waste should be disposed of using technology with the least possible impact on the environment [1]. Thus, different sorts of wastes should be disposed of using different methods.

The problem of waste includes the whole cycle: production use - disposal. When the waste material cannot be recycled, primary effort is to reduce its volume and then, considering its composition and technical properties, to technologically use it. The reduction of the waste volume may be more or less successfully performed by thermal treatment of waste. This technology exploits also the combustibility of waste, i.e. its energy content. Most of solid combustible waste has higher calorific value than quality brown coal. Thermal processes of waste disposal include combustion, gasification and pyrolysis. While combustion and gasification are exothermic processes that need oxygen supply, pyrolysis is an endothermic process requiring no oxygen. However, none of these technologies is totally harmless to the environment, since being thermal tech- nologies they all are, directly or indirectly, loaded with the negatives of the combustion process [2].

The aim of the research whose results are presented also in this contribution was to determine the energy potential (content) of selected MSW sorts and, using the obtained data, to advance a recommendation as to the method of their thermal treatment. To do so we have chosen selected waste samples for experimental measurements using laboratory pyrolysis apparatus.

\section{Selection of waste for experimental test}

The selection of samples was based on frequently present MSW components suitable for disposal using thermal technology. The possibility of their separation was also taken into account. Following components were chosen for experimental tests: packaging paper TP, newsprint - NP, cotton - BA, synthetic textile - PA, polypropylene - PP, polyethylene - PE, polyethylene-terephthalate - PET. Samples of selected waste components were subjected to the pyrolysis process and the energy content of the pyrolysis products was then evaluated. Due to insufficient analysis of plastic components their energy evaluation could not be made in full. Proximate and ultimate analysis of investigated samples prior to pyrolysis, determined by laboratory measurements, is given in Table 1 .

\begin{tabular}{|c|c|c|c|c|c|c|c|c|c|c|c|}
\hline Sample & Water & Ash & $\begin{array}{c}\text { Com- } \\
\text { bustible* }\end{array}$ & $\mathrm{C}^{\mathrm{d}}$ & $\mathrm{H}^{\mathrm{d}}$ & $\mathrm{N}^{\mathrm{d}}$ & $\mathrm{O}^{\mathrm{d}^{*}}$ & $\mathrm{~S}^{\mathrm{d}}$ & $\mathrm{Q}_{\mathrm{s}}$ & $\mathrm{Q}_{\mathrm{n}}$ \\
\hline \multicolumn{7}{|c|}{$[\% \mathrm{wt}]$} & \\
\hline TP & 5.55 & 15.25 & 79.2 & 36.84 & 5.19 & $<0.1$ & 39.23 & 0.02 & 13.21 & 11.93 \\
\hline NP & 5.89 & 26.42 & 67.69 & 37 & 4 & $<0.1$ & 30.77 & 0.06 & 12.02 & 11.05 \\
\hline PA & 0.40 & 0.31 & 99.29 & 51.5 & 4.1 & 0.4 & 43.64 & 0.05 & 15.81 & 14.90 \\
\hline BA & 5.11 & 0.96 & 93.93 & 45.3 & 6.9 & $<0.1$ & 46.58 & 0.11 & 15.87 & 14.31 \\
\hline
\end{tabular}

\footnotetext{
* Emília Wagnerová, David Uríček

Department of Power Engineering, Technical University of Košice, Faculty of Mechanical Engineering, Vysokoškolská 4, 04200 Košice, Slovakia
} 


\section{Apparatus for experimental measurements}

The design of the apparatus was based on a basic requirement of the pyrolysis method, which is an oxygen-free environment. In our apparatus the working space was filled with an inert gas - nitrogen. The material was heated by an electrical resistance furnace. In laboratory conditions, using laboratory apparatus, no continual operation was envisaged. When designing the apparatus the rate of pyrolysis, temperature in the working zone as well as the method of capturing the produced residues were also taken into account. The scheme of the apparatus is shown in Fig.1.

In order to prevent the penetration of air into the working space the pressure above atmospheric ( $100 \mathrm{~mm}$ of technological liquid) realized by liquid seal is maintained in the oven. Gas produced by pyrolysis is captured in the gas collecting vessel after bubbling through the technological liquid of the seal. It was necessary to choose such a liquid, which would not absorb the traced components since such an absorption would distort the results We used a solution of vinegar and water with the acidity of at least $4.5 \mathrm{pH}[3]$. The principle of our laboratory apparatus fully suits the requirements for a future technological solution of a pilot plant [4].

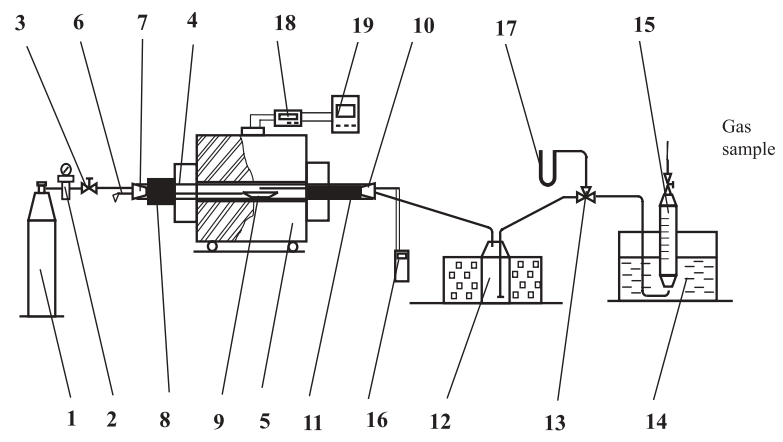

Fig. 1 Scheme of the laboratory pyrolysis apparatus 1 - cylinder of N2, 2 - pressure control valve, 3 - closing valve, 4 - furnace body (quartz tube), 5 - electrical resistance furnace,

6 - adjustable bar, 7 - input tube closing, 8 - feed-in chamber, 9 - combustion boat, 10 - output tube closing, 11 - output chamber,

12 - gas cooler, 13 - 3 - way valve, 14 - technological liquid, 15 - gas collecting vessel, 16 - Pt-RhPt thermocouple with thermometer Testo 945, 17 - U manometer, 18 - thermoregulator TC-31, 19 - electric supply meter

\section{Evaluation of experimental measurements}

Our aim was not to investigate pyrolysis as a technological process and thus verify what is already known [5-9]. The aim of our measurements was to determine the quantitative and qualitative energy content of the pyrolysis products and to compare them with the energy content of the original waste. The measurements were performed at three different temperatures $(600,800$ and $600 / 800$ ${ }^{\circ} \mathrm{C}$ ). All the samples, each with a mass of $0.5 \mathrm{~g}$, were subjected to pyrolysis under the same conditions and the decrease of the sample mass, the volume of the produced gas and its composition were observed during the pyrolysis process. The amount of the produced condensate could not be measured and so it was determined by computation based on the preservation of mass. The results of measurements are presented in the form of histogram. Fig. 2 shows the relative amount of pyrolysis residues.

It may be concluded from these graphs that the highest conversion of solid material into liquid and gas products is shown by plastic, while paper shows the lowest conversion degree. This may be connected with the ash content in the original sample. With increasing temperature the amount of the gas product increases while that of the solid product decreases.

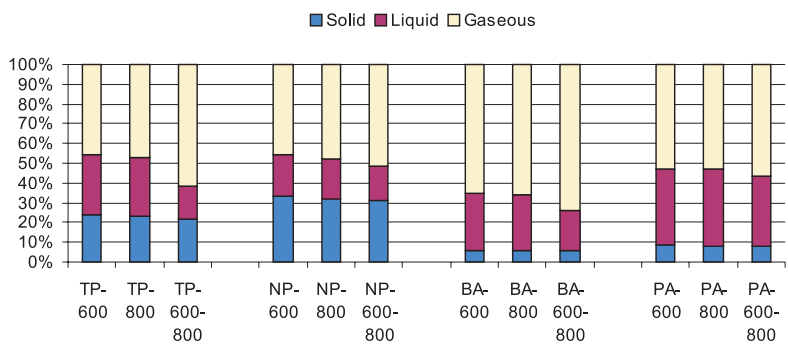

Fig. 2 Relative masses of individual pyrolysis products

We determined the calorific value of produced residues - pyrolysis gas and solid rest. To the calorific value of gas products contribute combustibles $\mathrm{CH}_{4}, \mathrm{H}_{2}, \mathrm{CO}$ and higher hydrocarbons. From their quantitative participation, at given temperature of pyrolysis, we determine the influence of particular components on the total calorific value. The relative content of particular combustible components at various temperatures for the gas product is shown in Fig. 3.

These graphs show that at higher temperature (i.e. $800{ }^{\circ} \mathrm{C}$ ) the yield of hydrogen increases in comparison to methane. At lower temperature the situation is reverse and the yield of methane is higher. CO content only slightly increases with the temperature, but, except for PE and PP, its content is generally high. From the energy point of view the pyrolysis seems quantitative richer in the gas product.

The energy balance of the products of waste pyrolysis depends not only on the calorific value of a product but also on the amount of these products. To be able to compare the energy potential of selected waste sorts before and after pyrolysis, for the final evaluation we transform all energy values into the thermal energy $[\mathrm{kJ}]$ of products and we compare them as such. Energy evaluation of the products produced by the pyrolysis of selected components of waste was performed for their solid and gas product. Liquid product of pyrolysis had insufficient volume for performing elemental analysis and so it was not accounted for in the energy evaluation. Thermal energies of selected sorts of waste before and after pyrolysis are given in Fig. 4. 

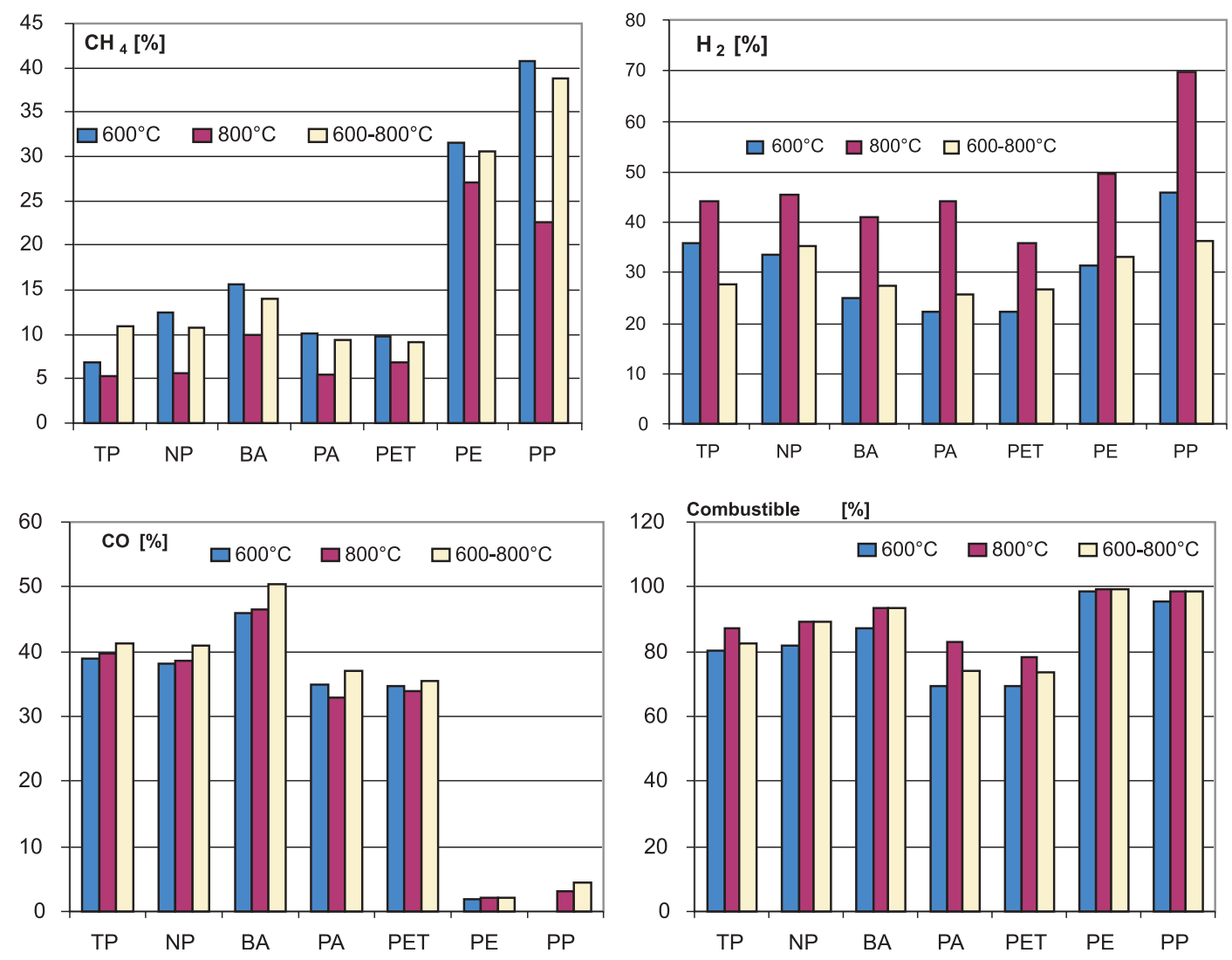

Fig. 3 Influence of temperature on $\mathrm{CH}_{4}, \mathrm{H}_{2}, \mathrm{CO}$ and combustible yield

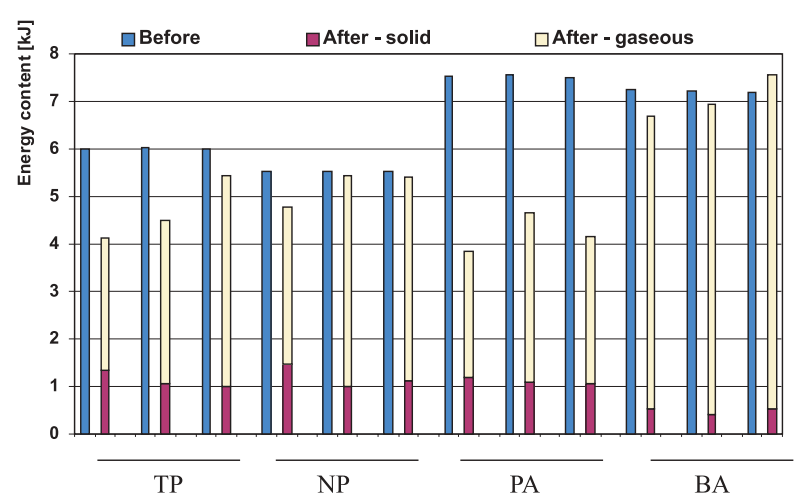

Fig. 4 Energy content of waste before and after pyrolysis

\section{Conclusion}

We can conclude that pyrolysis leads to the substantial reduction of the volume and mass of waste and that with the increasing temperature the volume of the produced gas increases. Considering the energy potential the pyrolysis seems to be quantitative richer in the gas product:

- $\mathrm{H}_{2}$ content is higher at the temperature of $800{ }^{\circ} \mathrm{C}$,

- $\mathrm{CH}_{4}$ content is higher at the temperature of $600{ }^{\circ} \mathrm{C}$,

- Pyrolysis gas contains a relatively high amount of $\mathrm{CO}$ (except for PP and PE).

On the basis of the obtained results we can recommend that for the disposal of PE, PP (plastics) and cotton (BA) it is suitable to use pyrolysis, for TP and NP (paper) incineration and for PA and PET gasification. When deciding on the use of a particular thermal treatment for the waste disposal it should be taken into account that pyrolysis is a method with endothermic reaction [10, 11 ] and, therefore, it is necessary to consider well if the use of this method is justified.

\section{Acknowledgements}

This work has been supported in part by the Scientific Grant Agency of Ministry of Education of the Slovak Republic and Slovak Academy of Sciences under the Grant No.1/9398/02 and 1/2918/05. The authors would like to thank for support that made this work possible. 


\section{References}

[1] EC Waste Framework Directive, EU, 1991.

[2] MOLČAN, P., KLENOVČANOVÁ, A., IMRIŠ, I.: Characteristic of harmful compounds incipient by the waste incineration [in Slovak]. - Acta Mechanica Slovaca, 3/2003 RAVYPaSE, SjF TU Košice, Košice, 2003, pp. 319-322.

[3] WAGNEROVÁ, E. URÍČEK, D: Pyrolysis of selected parts of MSW in laboratory conditions. - Systems, Vol. 9, Special Issue 2/2, Polish Systems Society, 2004. pp. 637-642.

[4] URÍČEK, D., BEŽOVSKÝ, M., VARGOVČÍK, V.: Laboratory apparatus for energy evaluation of MSW pyrolysis [in Slovak]. - Acta Mechanica Slovaca, 3-A/2004, SjF TU Košice, Košice, 2004, pp. 519-522.

[5] BRIDGWATER, A. V., GRASSI, G.: Biomass pyrolysis liquids upgrading and utilisation. - Elsevier, London - New York, 1991.

[6] KLASS, D. L.: Biomass for Renewable Energy, Fuels, and Chemicals. - Academic Press, London, 1998.

[7] LIN, K-S. et al.: Pyrolysis kinetics of refuse-derived fuel. - Fuel Processing Technology, No. 60, 1999, pp. 103-110.

[8] GARCIA, A. N. - MARCILLA, A. - FONT, R.: Thermogravimetric kinetic study of the pyrolysis of municipal solid waste. - Thermochimica Acta, 254 (1995), pp. 277-304.

[9] WU, CH.-H. et al.: Thermal treatment of coated printing and writing paper in MSW: Pyrolysis kinetics. - Fuel, No. 12, 1997, pp. 1151-1157.

[10] OBROUČKA, K.: Thermal waste disposal [in Czech]. - FMaMI VŠB - TU Ostrava, Ostrava, 1997.

[11] TÖLGYESSY, J., PIATRIK, M.: Water, Air and Solid Waste Technology [in Slovak]. - Chtf STU Bratislava, Bratislava, 1994. 